Economía, Sociedad y Territorio, vol. vIII, núm. 26, 2008, 517-548

\title{
La cuenca binacional del río Tijuana: un enfoque biohistórico
}

\author{
Lina OJEDa-ReVaH* \\ Martha Ileana Espejel-Carbajal **
}

\begin{abstract}
The basin of Río Tijuana, due to its binational character, allows us to compare and contrast two ways of space appropriation in a homogeneous physical unit, but very different from a socio-economical point of view. Historically, the population growth has been intimately linked to migrations rather than to natural growth and it has been fundamentally determined by economic events in the United Stated of America. The pattern of land usage is very different in both countries. In Mexico, the accelerated population growth and the lack of investment in infrastructure has given birth to a compact urban pattern and an increase in zones prone to flooding and landslides. In the United States the population growth, although also accelerated, was followed by strong investment in infrastructure. This translates into a more disperse urban pattern that derived into an urban interface in a forest zone naturally predisposed to fires.
\end{abstract}

Keywords: río Tijuana basin, land usage, bio-history, border, urbanisation.

\section{Resumen}

La cuenca del río Tijuana, por su carácter binacional (México-Estados Unidos), permite contrastar dos formas de apropiación del espacio en una unidad física homogénea pero muy diferente en lo socioeconómico. Históricamente, el crecimiento de la población ha estado ligado a migraciones, más que a un crecimiento natural, y determinado en lo fundamental por eventos económicos ligados a Estados Unidos. El patrón de usos del suelo es diferente en cada país. En México, el acelerado crecimiento de la población -sin la inversión en infraestructura- configuró un patrón urbano más compacto y aumentó en las zonas de riesgo por inundaciones, derrumbes y deslaves. El crecimiento en Estados Unidos, aunque también acelerado, se hizo a la par de una fuerte inversión en infraestructura y con un patrón urbano más disperso que derivó una gran interfase urbana en una matriz de vegetación que naturalmente está sujeta a incendios.

Palabras clave: cuenca del río Tijuana, uso del suelo, biohistoria, frontera, urbanización.

\footnotetext{
*Colegio de la Frontera Sur. Correo-e: lojeda@colef.mx.

**Universidad Autónoma de Baja California. Correo-e: ileana@uabc.mx.
} 


\section{Introducción}

Las referencias históricas son de gran utilidad para seguir la cronología y localización de los impactos humanos (Meyer y Turner, 1990). Las formas de apropiación y modificación que el ser humano ha ejercido sobre la naturaleza se analizan mediante la recuperación de los procesos históricos a través de lo que se ha denominado biohistoria (Boyden, 1992). Espacialmente, los límites de las cuencas son ideales para analizar la historia de los paisajes naturales y culturales y sus cambios a través del tiempo (Shugart, 1998), ya que son unidades ecosistémicas con características físicas homogéneas en las que se pueden contrastar formas de apropiación y transformación de la naturaleza, integrar las fuerzas que les dieron lugar y sus consecuencias ambientales. El estudio de las poblaciones humanas es una de las piezas más confiables, aun cuando no sean muy precisas (Lepart y Debussche, 1992) en las fuentes de documentación histórica. Las fotografías aéreas, las imágenes de satélite y las estadísticas de población se pueden usar para ligar la dinámica de ocupación territorial con la transformación de los paisajes, en el ámbito mundial (Meyer y Turner, 1990) o regional (Webster y Bahre, 2001).

En particular, la cuenca del río Tijuana es un área singular, tanto ambiental como socialmente, que comparten México y Estados Unidos (EU). Desde una perspectiva ambiental, presenta un clima de tipo mediterráneo que dio origen a comunidades naturales únicas en Norteamérica. Social y económicamente, se trata de una región fronteriza donde conviven dos culturas muy diferentes. En este entorno, ambos países han transformado el paisaje en un lapso muy corto y de forma diferente (mapa I).

Los análisis regionales históricos permiten visualizar de manera integral las transformaciones ambientales con las fuerzas que directamente les dieron lugar. La cuenca hidrográfica del río Tijuana, como unidad ecosistémica, provee un contexto significativo y manejable para analizar los cambios, ya que son unidades con ambientes físicos homogéneos en los que se pueden contrastar las diversas formas de apropiación de la naturaleza y sus consecuencias ambientales.

A pesar de que es una cuenca semiárida con recursos hídricos limitados, en ella se han desarrollado grandes centros urbanos. Conforme éstos crecieron, la demanda de agua aumentó hasta rebasar la capacidad de abastecimiento de las fuentes originales

y grandes inversiones y tecnología permitieron su transferencia 


\section{Mapa I \\ Transformaciones del uso del suelo y cobertura natural de la cuenca del río Tijuana (1953-1994)}
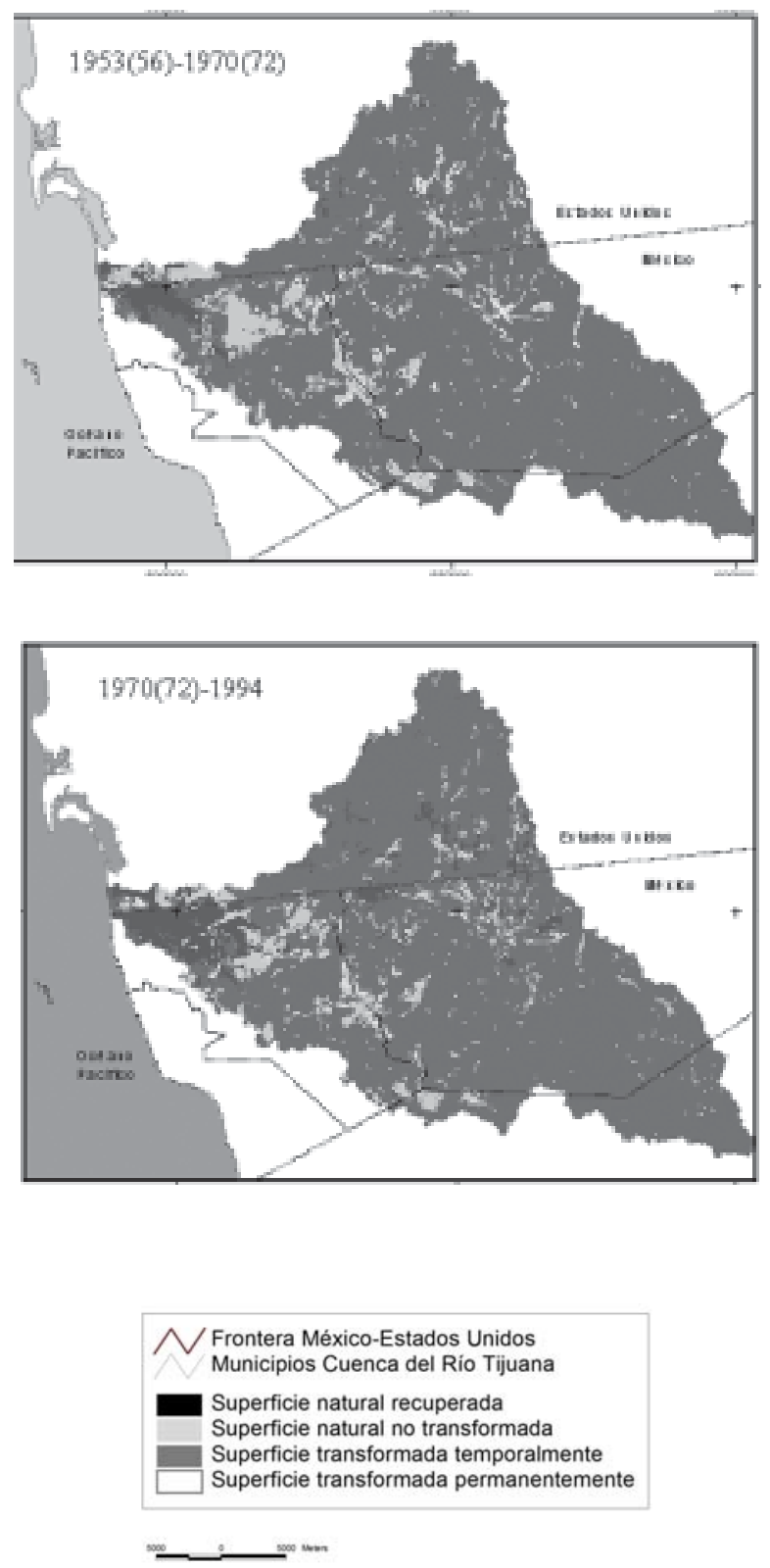

Fuentes: Interpretación de fotos aéreas de 1953 y 1956, Satélite Corona, y Defense Inteligence Agency, mapas de 1970 y 1994, metodología de acuerdo con Ojeda et al. (2007). 
desde cuencas más lejanas (Michel, 2002). Aunque siempre fue un factor de preocupación, al parecer el agua no fue lo que determinó el uso urbano. La complejidad de la historia del uso y manejo del agua en la región merece particular atención, que el presente artículo no incluye.

El trabajo forma parte de un estudio en el que con fotos aéreas de la cuenca del río Tijuana de 1953, 1956, 1970, 1972 y 1994 se construyeron mapas de tipos de vegetación y usos del suelo en un sistema de información geográfica, con el que se realizó un análisis espacial retrospectivo de los cambios ocurridos y descritos por Lina Ojeda (2000, 2002; Ojeda et al., 2007). El presente artículo constituye una fase inicial basada en la revisión bibliográfica y en estadísticas de población relacionadas con los resultados de la fotointerpretación y tiene como objetivo relatar los cambios ocurridos en la cuenca del río Tijuana, identificando las principales variables que los impulsaron y sus consecuencias espaciales. El estudio se realiza bajo los modelos conceptuales de la biohistoria y del ecosistema urbano, consistente en un sistema geográfico compuesto por tres subsistemas: el natural, el social y el construido (Herzog, 1990). Dado que el sistema es muy complejo, se consideran sobre todo la variable espacial (subsistema natural), la población, las políticas públicas (subsistema social) y los usos del suelo -urbano, agrícola y pastizales- (subsistema construido). Aunque el interés particular se centra en la cuenca del río Tijuana, mucha de la información citada se refiere a las ciudades de Tijuana y San Diego, no sólo porque éstas han rebasado las fronteras de la cuenca, sino porque su desarrollo ha influido en los cambios más trascendentes de la misma.

\section{El entorno natural de la cuenca del río Tijuana}

La cuenca del río Tijuana se ubica en el ángulo que forma la línea internacional entre México, eu y el Océano Pacífico. La región abarca 4,450 $\mathrm{km}^{2}$ de los cuales cerca de dos terceras partes se encuentran dentro del territorio mexicano (mapa I). Las mayores elevaciones se localizan en el extremo noreste, en el condado de San Diego, California, donde se alcanza una altura de 1,964 metros sobre el nivel del mar (msnm). En la parte mexicana la mayor altitud, de 1,850 msnm, se ubica en el extremo sureste, en la Sierra de Juárez. Casi toda la cuenca es montañosa y con una topografía accidentada. La desembocadura de las corrientes in- 
termitentes drena hacia el Océano Pacífico del lado de Eu. Se trata de una zona semiárida, con precipitaciones anuales que varían entre los 150 y los $500 \mathrm{~mm}$ anuales y con temperaturas medias anuales de ente 10 y $16^{\circ} \mathrm{C}$, siendo las partes con mayor altura las más húmedas y frías y viceversa (SDSU-COLEF, 2005).

La cuenca está cubierta por diversos tipos de vegetación. En las partes más elevadas del norte se localizan los bosques (mixtos y de pino); en las grandes altitudes del sur se encuentra el matorral de junípero y las praderas de alta montaña en las planicies de toda la cuenca. El chaparral es el tipo de vegetación más extendido, se distribuye entre 700 y 1,200 msnm, seguido del matorral costero, el cual generalmente crece por debajo de los $900 \mathrm{msnm}$. La vegetación riparia, flanqueando los cauces de arroyos, varía su extensión de manera proporcional con las corrientes de agua. Los usos del suelo se concentran principalmente en los valles y áreas planas.

\subsection{La cultura prehispánica}

Los primeros pobladores de la cuenca afectaron fuertemente su entorno con presiones de fuego y recolección de especies de flora y fauna, pero parecen haber estado en un equilibrio dinámico por más de un milenio (Blackburn y Anderson, 1993). ${ }^{1}$ Por el uso del fuego, es posible que hayan desarrollado un paisaje más humanizado que cualquier sociedad no agrícola haya creado (Aschmann, 1973).

Las culturas paleoindígenas o prehistóricas de San Dieguito y La Jolla dejaron restos del uso de recursos marinos y costeros en los litorales donde desemboca la cuenca, conocidos como concheros (Treganza, 1947; Rogers, 1945, 1966).

La primera cultura que habitó en el área fue la de los kumiai, la cual se extenió desde Torrey Pine, en California, hasta la zona central de Baja California (BC). Las evidencias sugieren su presencia en el valle del río Tijuana en tiempos de la llegada de los españoles (Shipek, 1969, 1993). Eran seminómadas y vivían en chozas hechas de ramas que abandonaban con el cambio de estaciones. Se procuraban sustento con base en la recolección, la caza o la pesca (Piñera y Ortiz, 1985). Modificaron el paisaje

\footnotetext{
${ }^{1}$ Estos autores compilaron una serie de artículos detallados sobre cómo manejaron el ambiente los nativos californianos al norte de la cuenca, pero que debieron ser muy similares al manejo de chaparrales y bosques del sur, como lo señala especialmente Florence Shipek (1993) para los kumeyaay.
} 
con métodos de manejo de suelo, labranza y uso del fuego. Usaban ramas para cavar, cosechar bulbos y tubérculos, aflojar y airear el suelo, así como para propagar plantas mejorando las cosechas subsecuentes. Aparentemente, utilizaban el fuego para manipular la arquitectura de arbustos, aumentar la reproducción de pastos y mejorar el acceso a las áreas de cosecha y de forraje para animales de caza (Barbour et al., 1993). Las versiones sobre los efectos de los incendios varían desde un régimen muy amplio provocado por rayos y la contribución ocasional de una hoguera de campamento, hasta un patrón deliberado de manejo de paisaje (Minnich, 1988).

Los kumiai se organizaban por clanes o bandas de familias extensas conocidas como sh'mules, los cuales aprovechaban o usufructuaban determinados territorios tradicionales y en ocasiones compartían con grupos más grandes arboledas, veredas, áreas de reunión de caza, ceremoniales o religiosas (Department of Landscape Architecture, 1989). Mantuvieron interacciones con tribus cercanas a través de una extensa red de intercambio de bienes e información de diversas zonas ecológicas desde el este hasta el río Colorado (Luomala, 1978).

\section{El encuentro de dos mundos}

Durante la Colonia, los cambios en el paisaje se hicieron más acusados. A las modificaciones ya impresas sobre la naturaleza por la forma de vida de los indígenas -con una extracción no intensiva en amplias zonas-, se añadieron las ocasionadas por la vida misional con otro tipo de perturbaciones y hacia otros recursos, con una explotación más intensiva y sobre zonas más reducidas al introducir la agricultura y la ganadería. Dada la escasa población, las modificaciones al paisaje no se pueden considerar de gran magnitud, salvo por la introducción de especies exóticas -especialmente en los pastizales inducidos para la ganadería- y la transformación de áreas originalmente ocupadas por matorral costero en campos agrícolas.

Las características geográficas de la península de Baja California ejercieron una gran influencia en su historia: "Su ubicación, separada del macizo continental del país, contribuyó a retardar el asentamiento de los españoles en ella y su aridez fue un factor limitante para el desarrollo de conglomerados humanos y originó prácticas especiales en la agricultura y la ganadería, con- 
dicionando las dimensiones de los predios utilizados, pequeños para los cultivos, enormes para la ganadería” (Piñera, 1991).

Las primeras noticias del establecimiento de los españoles en la región están registradas en los diarios de los misioneros franciscanos Junípero Serra y Juan Crespi, quienes en una expedición terrestre en 1769 fundaron en la Bahía de San Diego la primera misión en la Alta California. Sus descripciones del valle del río Tijuana son muy detalladas. La cañada El Matadero (Smuggler's Gulch) se ha identificado como la entrada al valle de fray Junípero Serra, mientras que el punto de entrada de fray Juan Crespi fue más al oeste. Este último se instaló en la parte sur del valle, cerca de un pueblo y lo describió como "una gran planicie de buena tierra, con mucho pasto verde [...] donde teníamos agua buena [...] Aunque la leña es escasa, las montañas que no están lejos, la tienen en abundancia” (Crespi, 1927). El padre Serra describe el lado norte del valle: "A corta distancia de cerca de una hora de camino, observamos que el campo no sólo eran buenos pastizales, sino que también tenía un río agradable de agua buena" (Serra, 1955).

Al llegar al noroeste de la península, los misioneros se encontraron con un entorno que en gran medida se asemejaba al de su tierra de origen: la Península Ibérica. La incorporación de los indígenas a las labores del campo les permitió conocer el entorno natural y desarrollar formas de apropiación de los recursos semejantes a las que ellos usaban antes: sistemas agropastoriles.

Con el desarrollo de la ganadería y la agricultura se inició una serie de transformaciones en el paisaje que afectaron especialmente los ecosistemas riparios, al matorral costero y a los pastizales. En esta época llegaron a la región al menos tres plantas exóticas y las primeras 200 cabezas de ganado, éste fue el inicio de una larga historia de introducción de especies no nativas, que para 1993 se calcula en 1,023 (Barbour et al., 1993).

La ganadería extensiva e itinerante realizada entonces es la misma que se practica en nuestros días en la sierras de Juárez y de San Pedro Mártir. Durante la época de lluvias, el ganado se alimentaba de las hierbas del matorral costero, de pastizales y de forrajes cultivados y en la temporada seca era conducido a las praderas de las montañas (Meling-Pompa, 1991). Esta actividad ocasionó que los pastizales nativos fueran sustituidos por pastos europeos (Minnich, 1983) y, posiblemente, que el matorral costero se tornara más atractivo para el ganado al producir la remo- 
ción selectiva de algunos arbustos que promovían el crecimiento de especies más palatables (Minnich y Franco-Vizcaíno, 1998).

Si bien es posible que los kumiai influyeran en la distribución del matorral costero, fueron los europeos quienes causaron que se redujera debido a que su distribución cubría las tierras bajas, relativamente fértiles (Aschmann, 1973). Sobre estas áreas, los misioneros cultivaron principalmente maíz, trigo y legumbres y cazaron venados, conejos y otros animales de la región (Santiago, 2002). Otros usos de los recursos incluyeron al matorral de Juniperus en las minas y como combustible para calentar y cocinar (Minnich y Franco-Vizcaíno, 1998) y en zonas riparias, los alisos para fabricar ruedas de carretas (Faber y Holland, 1988).

En este periodo las prácticas de uso de incendios fueron tan generalizadas, que en 1789 el gobierno de Arillaga pidió a los ciudadanos castigar a quienes prendieran fuego (Minnich, 1988).

\section{Los grandes cambios (siglo XIX)}

El siglo XIX se definió por la colonización de tierras y una actividad ganadera ampliamente extendida, pero sobre todo por el comienzo de dos historias muy diferentes (Eu y México) con consecuencias mutuamente dependientes.

Una vez que se estableció la misión de San Diego, el valle del río Tijuana se convirtió en un campo básicamente ganadero. Entre las rancherías indígenas que pertenecían a esta misión figuraba la de Tía Juana, de la que hay constancia desde 1809 (Piñera, 1991).

Con la formación de un México independiente, en 1822 comenzó en la península una política colonizadora mediante disposiciones legales que dieron el carácter de nacionales a los terrenos baldíos. Entre los primeros cambios que se registraron con estas disposiciones dentro de la cuenca, destaca la concesión de 4,500 ha otorgada a José Bandini a lo largo del arroyo Tecate en 1829 y el título de propiedad de 10,000 ha expedido en 1833 a Santiago Argüello en el valle del río Tijuana (Aguirre, 1987). Otras concesiones incluyeron dos ranchos más pequeños (San Ysidro y Jesús María) y el Rancho Milijó concesionado a Emigdio Ygnacio Argüello. Las rancherías establecidas de esta forma cobraron importancia por su cercanía con San Diego, donde vendían su producción ganadera que se incorporó al comercio con barcos extranjeros (Piñera y Ortiz, 1985).

Cuando se firmó el Tratado de Guadalupe Hidalgo en 1848, se crearon nuevos límites entre México y Eu: la cuenca se dividió 
en dos y comenzaron dos historias diferentes en la modificación del paisaje. La del lado de Eu, que se manifiesta con la incorporación de los recursos naturales a una economía de alto nivel de desarrollo, y la que se da en el lado mexicano, en la que por su aislamiento del centro del país y el poblamiento disperso, la modificación antrópica del paisaje fue poco significativa.

Durante este periodo, la fiebre del oro y la apertura de valles agrícolas fomentaron la migración masiva desde el este de Eu y otros países (de Asia y Europa) y el valle se convirtió en un territorio de bandoleros, robo de ganado y contrabando.

El sistema de reservaciones (concesiones de tierra) se implantó después de la firma de dicho tratado. La implementación de las políticas de reubicación y reeducación de los pueblos indígenas por parte del gobierno de los Estados Unidos, posteriores a las guerras indias de exterminio, desplazó a los kumiai (Department of Landscape Architecture, 1989). Por su parte, el sistema misional y las concesiones de grandes extensiones de tierra propiciaron que algunos clanes indígenas se refugiaran en las sierras y desiertos y se rebelaran constantemente, siendo reprimidos por los soldados de los presidios de San Diego, San Vicente o Guadalupe.

Para mediados de los cincuenta, el paisaje se transformó con el inicio de la tecnificación agrícola. La producción de trigo se extendió, superando la demanda local, por lo que el excedente se comenzó a exportar (Olmstead y Rhode, 2004). Sin embargo, en la segunda mitad del siglo XIX ambos lados de la frontera sufrieron un periodo de desatención política y económica, ya que en Eu estalló la guerra civil y México atravesó por un periodo de aguda inestabilidad económica y conflictos internos (Canales, 1996) que desembocaron en la Intervención francesa.

A pesar de esto, después de 1850 la ganadería creció en BC debido al aumento en el mercado de carne que provocó la fiebre del oro. En 1857 existían 43 ranchos con 8,620 cabezas. Inclusive los estadounidenses conducían su ganado por las cordilleras de México (Minnich y Franco-Vizcaíno, 1998). A principios de los sesenta, la municipalidad de la Frontera contaba con pequeños ranchos en las antiguas misiones. En ella habitaban 184 criollos y mestizos y 3,697 indios, principalmente yumas ${ }^{2}$ (Piñera, 1991). En la década de 1860, una serie de inundaciones y sequías devastó la

${ }^{2}$ Con este término se referían los misioneros, colonos y rancheros a los indígenas de la región del delta del Colorado, aunque ocasionalmente también lo usaban para el resto de los indígenas de filiación lingüística yumana (kumiai, paipai, cucapá, kiliwa, quechan, etcétera). 
ganadería, misma que se recobró hasta 1870 y se reorientó a la cría de borregos (Olmstead y Rhode, 2004). En 1872 el rancho de la Tía Juana poseía 900 reses y 500 caballos (Aguirre, 1987).

El origen de la actual ciudad de San Diego data de 1867, ${ }^{3}$ cuando Alonzo Horton compró 404 ha de tierra junto al mar. $\mathrm{Su}$ crecimiento y desarrollo principalmente se basó en una economía de bienes raíces, impulsada por el tren que conectaba con el este y por el descubrimiento de oro en el área de Julian en 1870 (Mills, 1967).

Hacia 1870, con el Porfiriato, la política de conquista territorial de Eu hacia México cambió por una de penetración financiera; en $\mathrm{BC}$ esta nueva estrategia se orientó hacia la urbanización (Piñera, 1991). De esta época (1876) data la fundación de la colonia agrícola de Tecate -entonces la población más grande del lado mexicano-, cuyas principales actividades eran la ya establecida ganadería y la minería impulsada por la fiebre del oro y el descubrimiento de diversos filones (Santiago, 2002).

En 1882 el ferrocarril, que ya había unido el norte de California con el resto de Eu, llegó a San Diego. Su presencia provocó grandes migraciones desde el este y con ello la especulación sobre las tierras californianas, misma que se extendió hasta Baja California. Un año después, debido a la promulgación de la Ley de Colonización en México, gran parte de la península quedó en manos de extranjeros, quienes abrieron nuevas tierras agrícolas y centros de población a través de fraccionamientos (Piñera, 1991). En esa época los Argüello comenzaron a fraccionar parte del rancho Tía Juana. Sin embargo, como en 1889 la compra-venta de terreno se suspendió y los precios se desplomaron, Tijuana creció lentamente (Piñera y Ortiz, 1985).

En 1886 Orcutt describió el área de Tijuana como extensos campos de fragmentos alternados de flores silvestres, sin embargo, según Minnich y Franco-Vizcaíno (1998), debido a que los viajes de Orcutt tuvieron lugar después de la segunda ola de entrada de especies exóticas, fueron éstas las que muy probablemente conformaban sus descripciones. De hecho, Orcutt no mencionó la presencia de pastos nativos y para esta época la agricultura de

\footnotetext{
${ }^{3}$ Para los estadounidenses la fundación de San Diego es 1867, para los mexicanos es 1769 , cien años de diferencia, lo importante es no perder de vista que el origen de varios poblados fue la fundación de los sitios misionales, los cuales, al ser secularizados o abandonados, se dieron en concesión para establecer ranchos, rancherías y, posteriormente, pueblos y ciudades. Véase María del Amparo Ruiz de Burton y Juan Bandini en www.San Diego Historical Society.
} 
temporal de avena y trigo ya se había extendido en el valle de Tijuana modificando la composición florística del área.

En 1889 inicia oficialmente la formación urbana de Tijuana al otorgarse un permiso para fundar la Villa Zaragoza. Gran parte del valle mantuvo actividades ganaderas durante casi todo el siglo XIX ya que San Diego se había convertido en el principal mercado de curtidos y sebos. Sin embargo, en el sur de California, después de 1880, la agricultura comenzó a sobrepasar a la ganadería, favorecida por la presencia del ferrocarril y por el acceso al mercado de eu. Entre 1890 y 1914 la economía de grandes ranchos y producción de granos de California (principalmente trigo) fue de menor escala, de cultivo de frutos, de riego y de industria de transformación (Olmstead y Rhode, 2004). Aunque en la región aumentó la población, siguió siendo escasa debido a que el número de indígenas había disminuido fuertemente.

Durante las últimas dos décadas del siglo, el paisaje experimentó una transformación sustancial, tanto por el desarrollo de tecnologías como por el aumento de la población. En la parte de EU se modificó el uso del suelo de ganadería a agrícola de riego. En el área de México las actividades comenzaron a transformarse de dependientes de los recursos naturales (ganadería y agricultura), a ser determinadas por procesos económicos, especialmente del sector servicios.

\section{Siglo xx. La primera Guerra Mundial y la ley Volstead}

Durante el siglo Xx, BC se caracterizó por un gran crecimiento demográfico y un proceso de concentración urbana acelerado. Aunque para 1921 la proporción de población urbana era baja, en 1930 alcanzó 55\%; en 1960, 72\%; en 1980, 85\% (Canales 1996), en $199091 \%$ y para el 2000, 92\% (INEGI, 2005). Este proceso de poblamiento derivó en una rápida apropiación del paisaje, especialmente en las partes bajas y planas de la cuenca, en donde se asienta la ciudad de Tijuana.

Fue a principios de este siglo cuando se inició el proceso de transformación del uso de suelo, de ganadero y en menor medida agrícola, hacia una forma de apropiación fundamentalmente urbana. Dada su localización fronteriza con eu, los patrones de uso dentro de la cuenca estuvieron más determinados por intereses económicos y por la solución de conflictos políticos, que por las propias limitantes biofísicas de los recursos existentes. 
En las primeras décadas del siglo xx hubo cambios en la configuración económica y espacial en ambos lados de la frontera. La terminación del monopolio de la compañía Commercial Pacific Mail Steamship, en 1905, abrió el puerto de San Diego a todos los barcos mercantes y junto con la apertura del Canal de Panamá en 1914, el área se desarrolló con importantes repercusiones para Tijuana (Piñera y Ortiz, 1985).

El ganado ovino introducido en el siglo xIX se juntaba en agosto cerca de Tijuana y regresaba en octubre, a veces desde la sierra de San Pedro Mártir (Henderson, 1964), a través de tierras de dominio público o rentadas. Entre 1885 y 1905 se llegó a conducir por esta ruta a casi 30,000 borregos al año para el mercado de Eu (Meling-Pompa, 1991). El pastoreo de este tipo de ganado se intensificó del lado mexicano en 1910, cuando el U.S. National Forest lo prohibió en las montañas del sur de California (Minnich, 1988). La agricultura de temporal producía cebada y avena para forraje y cuando la temporada de lluvias era propicia, se cultivaba frijol y maíz (Trava et al., 1991).

Con la participación de eu en la primera Guerra Mundial (1917) y la promulgación de una ley restrictiva se frenó la inmigración europea y asiática y aumentó la demanda de trabajadores mexicanos. En la agricultura se incrementó la producción de algodón (Olmstead y Rhode, 2004). La población estadounidense -impulsada por la introducción de la ley seca decretada en 1919visitaba Tijuana en busca de diversión, por lo que se desarrollaron los servicios turísticos. Tecate experimentó un desarrollo vertiginoso con el establecimiento de fábricas de whisky y malta (Santiago, 2002). En este contexto, importantes flujos de población del interior del país fueron atraídos hacia la frontera (Canales, 1996). Ese mismo año se estableció, por decreto presidencial, la colonia federal agrícola y ganadera Valle de las Palmas, con una superficie de 17,850 ha (Rodríguez, 1996).

Del lado de Eu, San Diego fue elegida sede del Departamento de la División de la Armada, lo que dio inicio a una larga historia de establecimiento de campos militares que demandaron espacio urbano para sus integrantes (Mills, 1967). Campos militares que aún conservan grandes extensiones de ecosistemas naturales.

Con la finalidad de resolver el problema de abastecimiento de mercancías a la frontera, dada la falta de comunicaciones con el interior del país, en 1933 se inició la política de zonas libres. Dicha medida tendría un fuerte efecto positivo sobre la economía de Tijuana (Canales, 1996). 
En la primera mitad del siglo comenzó la construcción de grandes obras de infraestructura como las presas Barret (1919-1922) y Morena (ampliada en 1930) en Eu; el ferrocarril de Tijuana a Tecate (1909-1919) y la Presa Abelardo L. Rodríguez (1936), en México. Paralelamente se inició la reforma agraria, con la cual se repartieron tierras, se empezó a poblar el área y se abrió el distrito de riego de dicha presa a lo largo de los ríos Tijuana y Alamar (Trava et al., 1991).

La política de zonas libres en Tijuana y la designación de San Diego como sede militar, sirvieron de propulsores económicos durante la década de 1930. Las tasas de crecimiento poblacional fueron de 6.9 y 3.2\%, respectivamente (INEGI, 2000; Sandag, 2000), aunque debe considerarse que en esa época San Diego ya rebasaba los 250,000 habitantes, mientras que Tijuana la duplicaba en proporciones de 11,000 a 22,000 (gráfica I). Asimismo, el ritmo de ocupación territorial de San Diego (333 ha/año) fue ocho veces mayor que el de Tijuana (40 ha/año) (Hiernaux, 1986; Aguilar Méndez, 1992, Gibson, 1998; gráficas II y III).

\section{Siglo xx. La segunda Guerra Mundial, la industrialización y el crecimiento urbano}

Con la intervención de eu en la segunda Guerra Mundial (19411945) se favoreció una vez más la migración laboral. En San Diego se construyó una importante base militar que benefició a Tijuana con comercio, turismo y la contratación de mano de obra para sostener la producción económica y militar. Esto condujo a la firma de los acuerdos entre México y Eu conocidos como Programa Bracero (1942-1964), los cuales proveían mano de obra mexicana a la economía de Eu (Zenteno y Piñeiro, 1992). Mientras las ciudades crecían, la ganadería comenzó a resurgir -fuera de la producción de leche- tanto en San Diego (Olmstead y Rhode, 2004) como en Baja California (Lorey, 1990) (gráfica IV). La actividad ganadera en los ejidos del norte de Baja California era de 2,788 cabezas de ganado vacuno, 1,497 caprinos, 8,006 porcinos y 1,508 equinos (Secretaría de la Economía Nacional, 1942). Con la actividad generada en la región por la segunda Guerra Mundial, la década de los cuarenta registró una de las tasas de crecimiento de población históricamente más altas, con 10.8\% en Tijuana y 6.6\% en San Diego (INEgI, 2000; Sandag, 2000). Tijuana se extendió espacialmente a un ritmo parecido a la década 


\section{Gráfica I}

Tasa de crecimiento de la población de Tijuana y San Diego

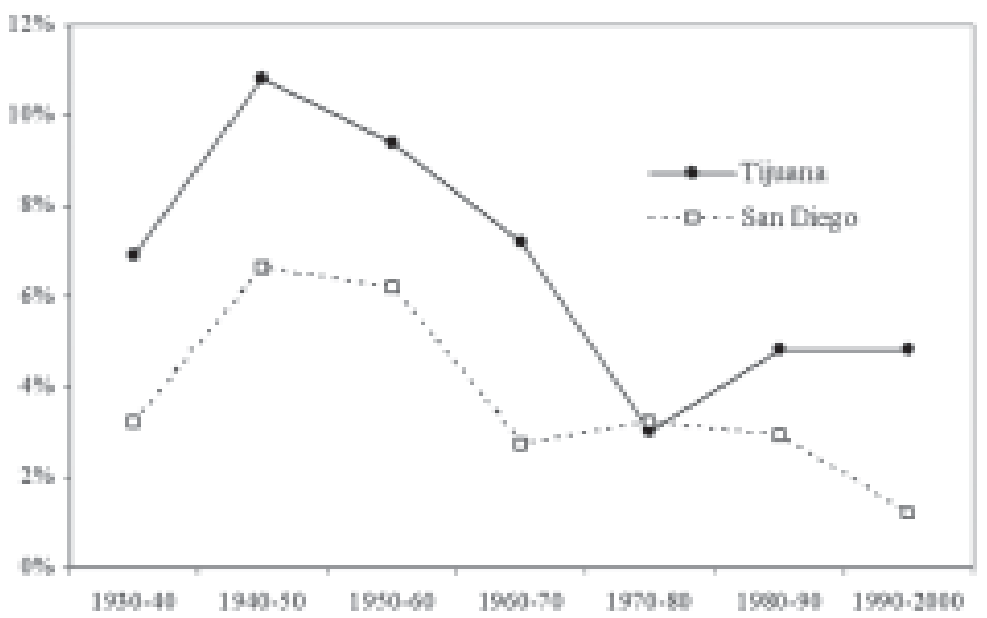

Fuentes: Población INEGI (2000) y Sandag (2000).

\section{Gráfica II}

Velocidad de crecimiento de la superficie urbana de Tijuana y San Diego (1930-2000) en has/año

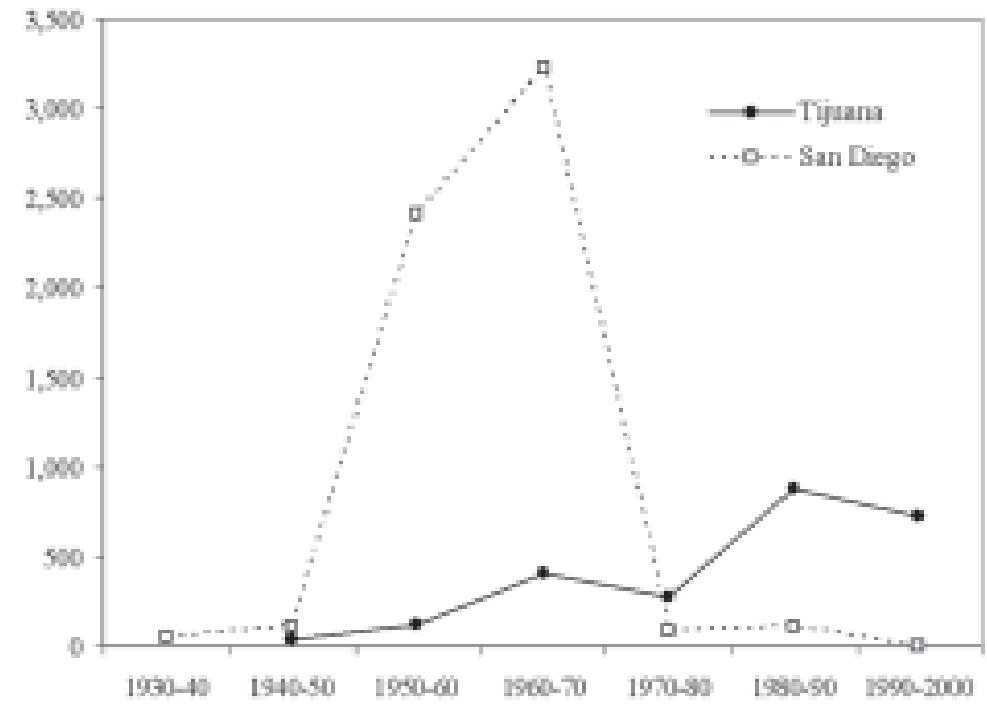

Fuentes: México 1930-1950, Aguilar Méndez (1992), Hiernaux (1986); 1980, Ranfla et al. (1986), Bringas y Sánchez (2006); Gibson (1998) y Sandag (2000). Nota: 194050 Tijuana es de 1935-50. 


\section{Gráfica III \\ Densidad de la población de Tijuana y San Diego (1930-2000) en hab/has}

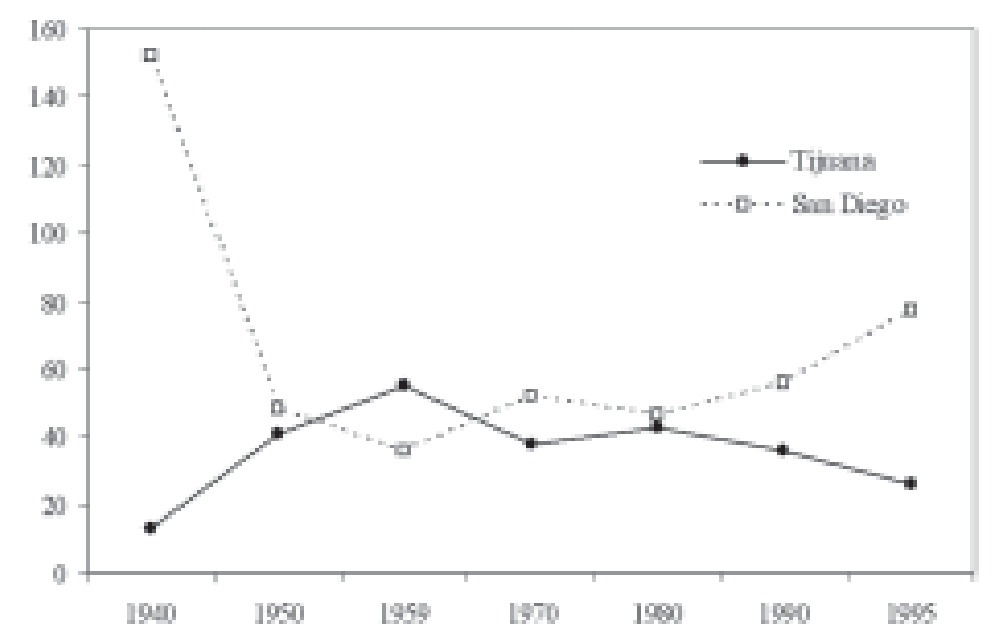

Fuentes: México 1930-1950, Aguilar Méndez (1992), Hiernaux (1986); 1980, Ranfla et al. (1986), Bringas y Sánchez (2006); Gibson (1998) y Sandag (2000). Nota: 194050 Tijuana es de 1935-50.

\section{Grafica IV}

Evolución de la ganadería en Baja California (1930-1990)

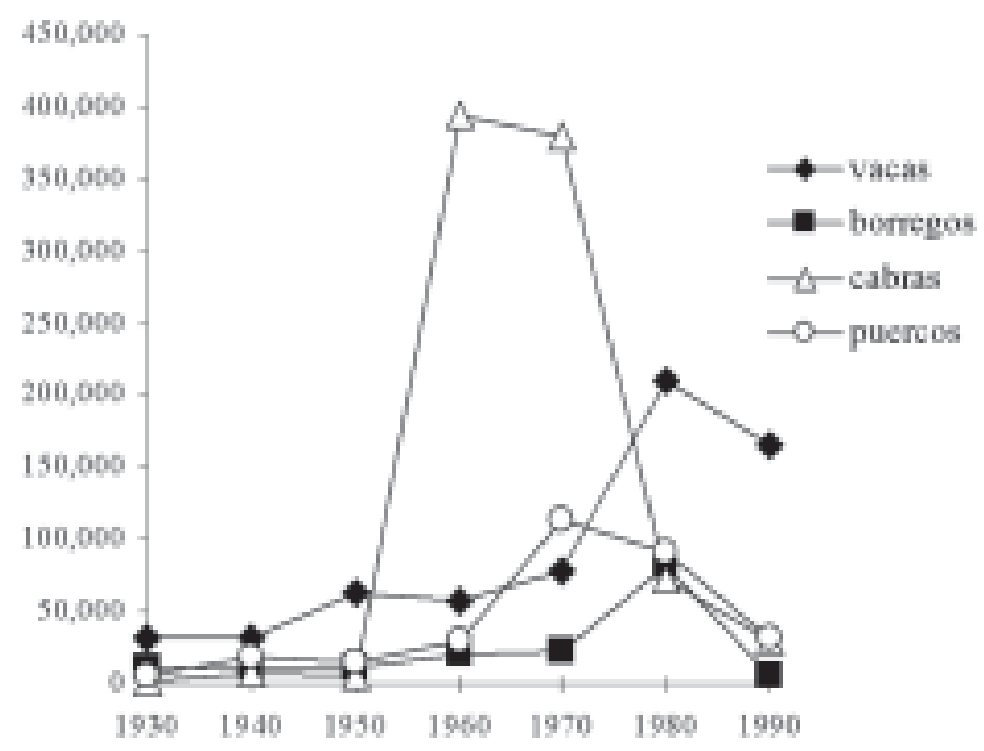

Fuentes: Lorey (1990) e INEGI (1991) 
anterior (40ha/año) y San Diego lo redujo a 106.2 ha/año (Hiernaux, 1986, Aguilar, 1992, Gibson, 1998) (gráficas I y III).

En los cincuenta la población de San Diego y Tijuana siguió creciendo, lo que incrementó la presión sobre el territorio y Tecate también comenzó a figurar en términos de población y superficie. Se inició entonces un proceso de urbanización-industrialización que desplazó a las actividades primarias como las principales captadoras de mano de obra y de generación de riquezas. También ocasionó que se redujeran las áreas de vegetación natural, cediendo su espacio principalmente al desarrollo urbano, a la agricultura y a la ganadería extensiva, ligadas a la demanda del mercado estadounidense.

En EU, la combinación de la política de hipotecas (Housing Administration's Mortgage establecida en 1934) originalmente creada para proteger a los dueños de casas de zonas con poca densidad de población, con facilidades de pago y el decreto de construcción de carreteras interestatales (Interstate Act, iniciada en 1956), fomentaron la dispersión de la población en suburbios (EPA, 2005) y la agricultura se transformó hacia la producción de viveros de plantas de ornato y flores (Sokolow, 2004). En México, las zonas ganaderas aledañas a Tijuana cambiaron al cultivo de cereales, hortalizas, vides y frutales al transformarse en ejidos. No obstante, una prolongada sequía durante los años cincuenta obligó a los poseedores de parcelas a venderlas en forma de fraccionamientos (Trava et al., 1991). Aparentemente, en esa época aumentó de forma desproporcionada la cría de cabras (casi 40,000 cabezas) en BC (Henderson, 1964), con el consecuente impacto sobre los ecosistemas (gráfica IV).

Aunque las tasas de crecimiento de la población disminuyeron, siguieron siendo altas: $9.4 \%$ en Tijuana y $6.2 \%$ en San Diego (INEGI, 2000, Sandag, 2000) y el aumento espacial de ambas ciudades fue muy diferente. Promovida por la política de construcción de carreteras en EU, San Diego se expandió a gran escala ocupando 2,409 ha/año, mientras que Tijuana mantuvo una ocupación de 121 ha/año (Aguilar Méndez, 1992; Gibson, 1998) (gráfica I). La urbanización de Tijuana comenzó a rezagarse por presiones de la creciente población que demandaba espacio y aparecieron asentamientos precarios en la periferia (Páez, 2005).

Entre 1940 y 1960, el sector manufacturero de Tijuana se duplicó y aumentó la industria de la construcción, aunque los servicios siguieron siendo más importantes (Zenteno y Cruz, 1992), Tecate estableció industrias cerveceras y vinícolas (San- 
tiago, 2002), se desarrolló la infraestructura de transporte (ferrocarril Sonora-BC y la carretera Tijuana-Mexicali), solventando parte del aislamiento de la región con el centro de México, y resurgió la ganadería en ambos lados de la frontera (Olmstead y Rhode, 2004; Lorey, 1990).

\section{El impulso de las maquiladoras en Tijuana}

Posteriormente, la industria estadounidense se reestructuró y con ello culminó el Programa Bracero en 1964. Miles de trabajadores tuvieron que regresar a México por falta de oportunidades de trabajo en eu y la economía de la frontera fue incapaz de absorberlos. El gobierno mexicano creó entonces el Programa de la Industrialización de la Frontera (PIF) en 1965, con el que se permitía a todas las zonas libres de impuestos importar materias primas sin restricciones y crear empresas con 100\% de capital extranjero si los productos eran exportados (Zenteno y Cruz, 1992). Como consecuencia de estas medidas, numerosas plantas -en especial ensambladoras o maquiladoras fuertemente integradas con la economía de EU- se trasladaron a la frontera impulsando la industrialización de la zona (Salas, 1989).

Durante la década de los sesenta, en Tijuana continuó el impulso al sector industrial y se inició otro periodo de construcciones con la canalización del río, la carretera transpeninsular y la presa el Carrizo. Para esta época, ya sólo se cultivaba 20\% del valle (Dedina, 1995). La ganadería de borregos de libre pastoreo disminuyó porque el aumento de la agricultura desalentó la renta de tierras de pastoreo y porque en 1964 se prohibió esta práctica (Meling-Pompa, 1991). Durante esta década siguió una tendencia hacia la baja en las tasas de crecimiento poblacionales, siendo más notoria en San Diego (2.7\%) que en Tijuana (7.2\%) (INEGI, 2000, Sandag, 2000). A pesar de ello, en parte por la inversión en infraestructura en el lecho del río Tijuana y por el desplazamiento hacia la periferia de los habitantes de esta zona, Tijuana incrementó su ritmo de ocupación del territorio a 408 ha/año (Hiernaux, 1986), rebasó los límites del valle y comenzó a ocupar las laderas que la rodeaban, mientras que Tecate creció a 20 ha/año. San Diego, por su parte, continuó con el impulso de carreteras y suburbanización y alcanzó una ocupación espacial histórica de 3,225 ha/año (Gibson, 1998; gráfica v).

A mediados de los setenta, con la recesión económica en Eu, muchas maquiladoras cerraron. La sobrevaloración del peso en 


\section{Gráfica V}

Tasas de crecimiento urbano por grado de pendientes (1972-2000)

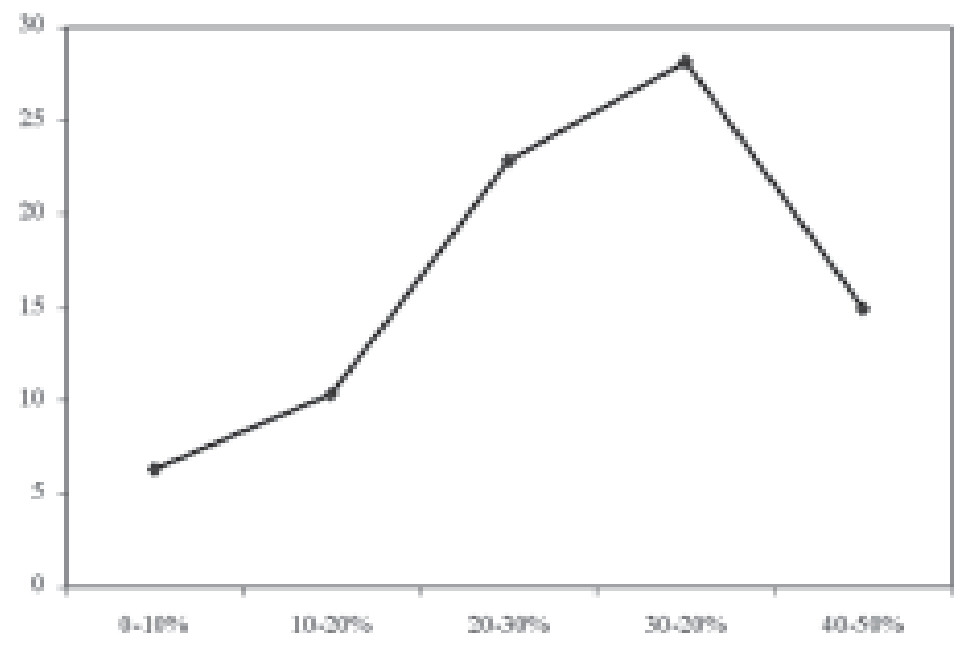

Fuente: Bringas y Sánchez, 2006

esta década provocó que la mano de obra perdiese atractivo en el mercado mundial, lo que tuvo un efecto negativo en el desarrollo de Tijuana (Zenteno y Cruz, 1992). En el ámbito federal en México, en 1970 se inició una política de impulso a la ganadería (Programa Nacional Ganadero), cuyo objetivo era abastecer de carne a la población urbana (Challenger, 1998). En Baja California este programa se reflejó en un aumento explosivo de ganado vacuno, al pasar de 63,044 cabezas en 1950 (Lorey, 1990) a 210,571 en 1980 (INEGI, 1991) y en el crecimiento del área de pastizales dentro de la cuenca (gráfica II mapa I).

Por estas razones, entre 1970 y 1994, según nuestro análisis, dentro de la cuenca se perdieron cerca 2,500 ha de agricultura de riego en la parte de Eu, a razón de 102 ha/año y aparentemente los pastizales (aunque parte de estos pueden ser para agricultura en periodo de descanso). Estos datos coinciden con lo que se informó para el condado de San Diego acerca de la pérdida de zonas agrícolas y pastizales de casi 20,000 ha entre 1984 y 2002 a razón de poco más de 1,000 ha/año, principalmente por desarrollo urbano (California Department of Conservation, 2002). En la superficie mexicana de la cuenca, la agricultura de riego estaba concentrada sobre todo en el Valle de las Palmas y entre 1972 y 1994 perdió casi 500 ha a razón de, en promedio, 23 has/año. Aunque la agri- 
cultura de temporal muestra variación en cuanto a su extensión, dependiendo de las condiciones climatológicas, nuestros resultados indican que en 1972 existían 7,745 ha y para 1994, poco más 8,700 ha debido a las lluvias. En resumen, en el conjunto de la cuenca las agriculturas de riego, de temporal y la ganadería disminuyeron (en 1972 ocupaban casi 9\% de la superficie y para 1994 se habían reducido a 7.65\%) (mapa Ia).

Por otro lado, las tasas de crecimiento de la población durante los setenta disminuyeron drásticamente en Tijuana (3\%) y aumentaron un poco en San Diego (3.2\%) (INEGI, 2000; Sandag, 2000). Espacialmente Tijuana creció a 269 ha/año (Hiernaux, 1986; Ranfla et al., 1986), con lo que rebasó los límites de la cuenca y multiplicó el ya existente rezago en construcción de infraestructura y servicios. San Diego, por el contrario, disminuyó en forma dramática la velocidad de ocupación de su territorio a 80 ha/año (Gibson, 1998; gráficas I y II). El resultado de este crecimiento poblacional concentrado en las tres principales ciudades (San Diego, Tijuana y Tecate) se refleja en la mancha urbana, la cual creció dentro de la cuenca de 10,524 a 30,806 ha entre 1970 y 1994. En la parte mexicana aumentó de 6,962 a 22,102 ha a razón de 1,262 ha/año. Las zonas urbanas más grandes son Tijuana y Tecate. La primera, en 1972 concentraba 78\% de su extensión dentro de la cuenca y en 1994, 87.5\%. La segunda está contenida completamente dentro de la cuenca. En la parte estadounidense de la cuenca, el crecimiento urbano se dio de 3,562 a 8,704 ha a razón de 367 ha/año. La zona urbana más grande dentro de la cuenca es parte de San Isidro (única considerada dentro de la zona metropolitana de San Diego) que en 1994 abarcaba aproximadamente 3,350 ha. Otras zonas urbanas incluyen Pine Valley, Morena Village y muchas de baja densidad (más de 100) (mapa ib).

Debido a la drástica devaluación del peso, durante los ochenta en Tijuana los servicios crecieron una vez más, con una contribución mayor a la de la industria. La economía de la maquiladora creció a tasas nunca antes vistas (Zenteno y Cruz, 1992), al pasar de 123 en 1980 a 690 en 1990 (INEGI, 2005; gráfica VI). Con ello, la población creció una vez más a 4.8\% (INEGI, 2000), lo que ocasionó una ocupación espacial sin precedente de casi 880 ha/año (Ranfla et al., 1986; INEGI, 1990), principalmente en áreas con pendientes mayores de 30\% e inclusive de 40\% (Bringas y Sánchez, 2006). San Diego, aunque disminuyó su crecimiento poblacional a $2.9 \%$ 


\section{Gráfica VI \\ Número de plantas maquiladoras y de empleos asociados \\ (1975-2005)}

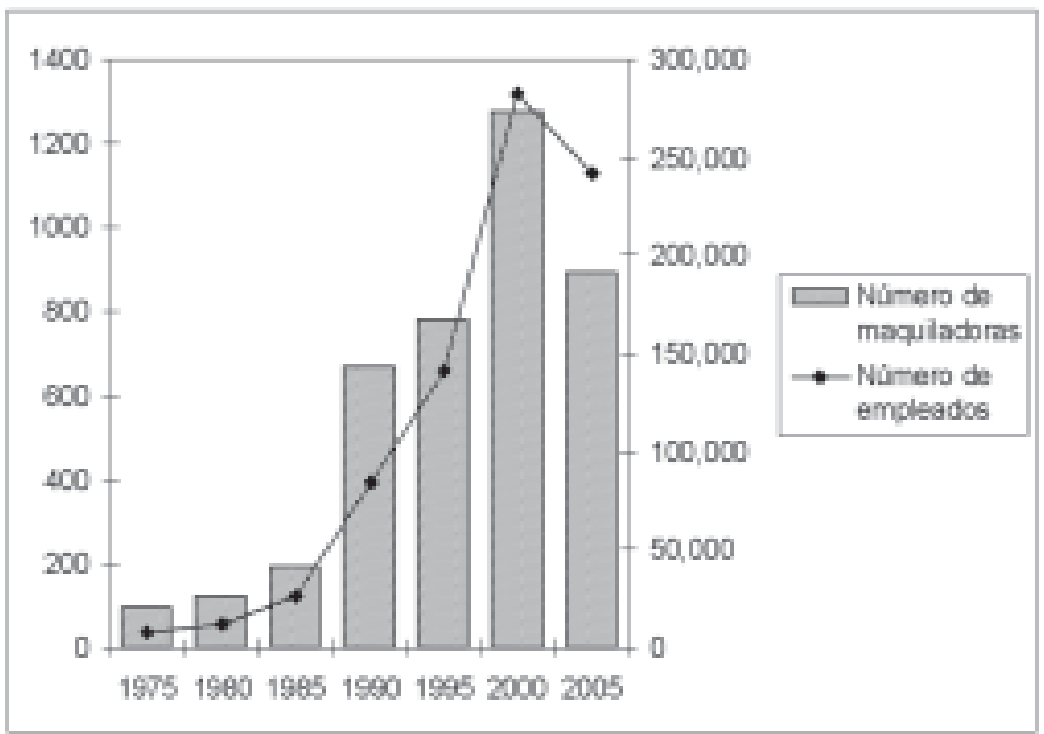

Fuente INEGI, 2005, Industria maquiladora de exportacion http://dgcnesyp. inegi.gob.mx/ cgi-win/bdieintsi.exe/NIVJ150002000300050005\#ARBOL?c=1414.

(Sandag, 2000), volvió a aumentar su ocupación territorial a 103 ha/año (Gibson, 1998; mapa I, gráficas I, II y III).

Con el Tratado de Libre Comercio (TLC), firmado en 1994, México se abrió a corporaciones extranjeras en busca de mano de obra barata. En 2002, el TLC borró las exenciones especiales de impuestos para maquiladoras. En términos de población, la década de los noventa registró tasas de $4.8 \%$ y $1.2 \%$ para Tijuana y San Diego, respectivamente (INEGI, 2000; Sandag, 2000). Tijuana creció a un ritmo de 725 ha/año y para el 2000 ya se extendía sobre una superficie de 26,045 ha (Bringas y Sánchez, 2006; INEGI, 1991). Al contrario de San Diego que frenó su crecimiento (Sandag, 2000), en parte por el inicio de la política de conservación de ecosistemas Multiple Species Conservation Program (MSCP, 2003; mapa I y gráfica II).

Aunque con variaciones a lo largo del tiempo, en promedio la densidad de población entre 1950 y 2000 siempre fue más elevada en Tijuana que en San Diego: 42 hab/ha y 12 hab/ha, respectivamente (gráfica III). Los patrones de ocupación del espacio generaron diferentes tipos de riesgos de cada lado de la frontera. 
Por ejemplo, los incendios en esta región son parte de la dinámica natural que evolutivamente han desarrollado los ecosistemas naturales y requieren de ellos para su permanencia (Keeley y Keely, 1984; O’Leary, 1990; comparar mapas I a y b).

Desde 1900, en California se inició una política de supresión organizada de incendios debido a una preocupación creciente respecto de la protección de cuencas, ciclos de inundaciones, erosión y daño a la propiedad. La rápida expansión dispersa de San Diego después de la segunda Guerra Mundial creó una larga frontera urbana entremezclada con ecosistemas naturales, aumentando el riesgo de incendios. El histórico rezago de urbanización en Tijuana, por el contrario, influyó en que la ocupación del territorio fuera más compacta y con menor perímetro entre lo urbano y la vegetación natural (mapa ib), ya que la población recién integrada buscaba estar cerca de los servicios. En BC, inclusive hoy en día, los incendios no son controlados y tradicionalmente los provocan los ganaderos y lo interesante es que, según Minnich y Franco-Vizcaíno (2002), el tamaño e intensidad de los incendios es menor que los que se registran en San Diego.

A diferencia de San Diego, Tijuana presenta un mayor riesgo de inundaciones, derrumbes y deslaves. Localizada en un valle muy estrecho y con topografía accidentada, así como con un crecimiento explosivo de la población y de maquiladoras sin un esquema de planeación, Tijuana se rezagó en la construcción de drenaje y progresivamente ocupó zonas poco aptas para uso urbano. Entre 1972 y 1989, la mayor parte del crecimiento se dio sobre pendientes de 20 a 30\%, entre 1989 y 1994 sobre pendientes de 30 a 40\% y entre 1994-2000 sobre terrenos con 40\% de inclinación (Bringas y Sánchez, 2006; gráfica v).

La intensa modificación del paisaje de la cuenca continúa en la parte baja de la misma hacia Tecate. Es importante intentar que se mantenga la conexión entre los ecosistemas de México y $\mathrm{EU}$, porque como se ve en el mapa I, lo urbano se está cerrando en una barrera que impedirá la conectividad entre los sistemas naturales. La cuenca alta, aunque se ha transformado principalmente por la ganadería, mantiene su carácter natural y por tanto aún no se ha modificado su función ecológica.

\section{Conclusión}

La biohistoria de la cuenca del río Tijuana permite reconocer dos características de la transformación ambiental: a) que es un 
proceso que invariablemente contiene interacciones humanas y ambientales complejas, donde los usos humanos tienen numerosos efectos sobre la naturaleza cuyas consecuencias pueden revertirse, en diferentes grados, hacia los propios usos de la región y b) las áreas varían mucho según las escalas y los tipos de transformación a que hayan sido sometidas (Turner et al., 1990; Boyden, 1992). La población en sí, así como su número, no necesariamente constituye una causa directa de la degradación ambiental. Es también a través de las modalidades de desarrollo que la población ejerce una acción que cambia el paisaje y aumenta las zonas de riesgo, al estar determinadas fundamentalmente por las características de los sistemas productivos y de la ocupación del espacio y no sólo por el número de individuos.

En el caso de la cuenca entre dos países, las causas de la transformación del entorno natural pudieron ser las mismas, pero los cambios tienen diferentes expresiones en el uso del suelo, como han demostrado casos estudiados alrededor del mundo (Boyden, 1992; Shugart, 1998).

Las variables determinantes de la ocupación espacial del ser humano en la cuenca han estado relacionadas con el crecimiento de la población ligado a migraciones, la implementación o ausencia de políticas públicas, ya sea en forma de leyes o de programas (con sus inversiones) y las guerras. En consecuencia, se crearon diversos patrones de ocupación del espacio que generaron, además de las externalidades ambientales (problemas de drenaje, contaminación atmosférica, desechos tóxicos) descritas por Herzog (1990) y diferentes tipos de riesgos (deslizamientos, erosión, incendios).

La ganadería, aunque extensiva, no ha transformado mucho al paisaje, salvo durante la década de los setenta cuando fue muy fuerte e impulsada por una política federal. Sin embargo, los pastizales parecen constituir una fase previa al desarrollo urbano. La agricultura de riego, por sus requerimientos de infraestructura, está circunscrita a lugares determinados (como el Valle de las Palmas en la porción mexicana de la cuenca). La agricultura de temporal -actividad que sólo se realiza en México- hace más compleja la dinámica de cambio del paisaje en la cuenca, dada su característica efímera, dependiente de las lluvias y su movilidad espacial. En el aspecto urbano, eu ha respondido a las contingencias ambientales provocadas por su crecimiento disperso al crear un programa de reducción de riesgos por incendios vía el aclareo selectivo cerca de las casas y otras medidas (Gilmer, 1994), fre- 
nó su crecimiento urbano (gráfica II; EPA, 2005) e impulsó un programa de conservación para combatir la pérdida de los ecosistemas naturales y su fragmentación (MSCP, 2003). En México, la centralización, el escaso presupuesto para urbanización otorgado a los municipios y una racionalidad de planeación por sectores económicos, más que una lógica espacial o regional, son algunos de los problemas de planeación de uso del suelo (Herzog, 1990). En el ámbito estatal no se han implementado políticas de conservación (áreas protegidas) y aunque se han decretado Programas de Desarrollo Urbano (PDU) y de Ordenamiento EcológiCo (OE) (POE, 1995), pocas veces se respetan. Recientemente se publicaron nuevos PDU y OE cuya visión complementaria considera la prevención de riesgos (POE, 2004, 2005). La actualización periódica de este estudio será motivo de otras publicaciones y se podrá evaluar el éxito o fracaso de dichas políticas.

Agradecemos los comentarios de Rosa Imelda Rojas, Richard Wright y Moisés Santos, así como a Zenia Saavedra por la edición de los mapas.

\section{Bibliografía}

Aguilar Méndez, Fernando Antonio (1992), La expansión territorial de las ciudades de México, Universidad Autónoma Metropolitana, manuscrito, México.

Aguirre, Celso (1987), Breve historia del estado de Baja California, Ediciones Quinto Sol, Mexicali, B.C.

Aschmann, Homer (1973), "Man's impact on the general regions with Mediterranean climate", en F. di Castri y M. Mooney (eds.), Mediterranean Type Ecosystems, Nueva York, Springer-Verlag, pp. 363-371.

Barbour, Michael, Bruce Pavlick, Frank Drysdale y Susan Lindstrom (1993), California's Changing Landscapes, Diversity and Conservation of California Vegetation, California's Native Plant Society, California.

Blackburn C., Thomas y Kat Anderson (comps.) (1993), Before the Wilderness, Environmental Management by Native Californians, Ballena Press, California. 
Boyden, Stephen (1992), "Biohistory: the Interplay between Human Society and the Biosphere-Past and Present", $M A B$, 8, unesco-The Parthenon Publishing Group, París, p. 265.

Bringas, Nora y Roberto Sánchez (2006), "Social vulnerability and disaster risk in Tijuana: Preliminary findings", en Jane Clough-Riquelme y Nora Bringas (eds.), Equity and Sustainable in the US-Mexico Border Region: Reflections from the U.S. Mexico Border, University of California, San Diego, pp. 149-173.

California Department of Conservation (2002), 1984-2002, San Diego County Land Use Summary, Farmland Mapping and Monitoring Program, en <http://www.consrv.ca.gov/ DLRP/fmmp/pubs/1984-present/SDG_1984_2002.xls>, marzo de 2006.

Canales, Alejandro (1996), "El poblamiento de Baja California, 1848-1950”, Frontera Norte, 7(3), México, pp. 6-23.

Challenger, Anthony (1998), Utilización y conservación de los ecosistemas terrestres de México, pasado presente y futuro, Comisión Nacional para el Conocimiento y Uso de la Biodiversidad-Universidad Nacional Autónoma de México-Agrupación Sierra Madre, México.

Crespi, Juan (1927), Fray Juan Crespi, Missionary Explorer on the Pacific Coast, 1769-1774, ed. de Herbert Eugene Bolton, Ams Press, Nueva York.

Department of Landscape Architecture (1989), A management framework for the Tijuana River Valley, San Diego County, San Diego.

Dedina, Serge (1995), “The political ecology of transboundary development: land use, flood control and politics in the Tijuana River Valley", Journal of Borderlands Studies, x(1), Institute of Regional Studies of the Californias, San Diego State University, San Diego, California, pp. 89-110. 
EPA (Environmental Protection Agency) (2005), About Smart Growth, en <http://www.epa.gov/smartgrowth/about_ sg.htm >, marzo 2006.

Faber, Phyllis M. y Robert F. Holland (1988), Common Riparian Plants of California. A Field Guide for the Layman, Pickleweed Press, California.

Gibson, Campbell (1998), "Population of the 100 largest cities and other urban places in the United States: 1790-1990", Population Division Working Papers, 27, U. S. Bureau of the Census, Washington, D. C., en <http://www.census. gov/population/www/documentation/twps0027.html>, marzo de 2006.

Gilmer, Maureen (1994), California Wildfire Landscaping. Creating Bands of Protection with Plants Managing Native Vegetation Getting Help: Public and Private Resources. How to Comply with the High Fire Zones Law, Taylor Publishing Company, Dallas, Texas.

Henderson, David (1964), "Agricultural and Stock Raising in Baja California", PhD Dissertation, University of California (Los Ángeles).

Herzog, Lawrence (1990), Where North Meets South. Cities, Space and Politic on the U.S.-Mexico Border, University of Texas, Austin, Texas.

Hiernaux, Daniel (1986), Urbanización y autoconstrucción de vivienda en Tijuana, Centro de Ecodesarrollo, México.

INEGI (Instituto Nacional de Estadística, Geografía e Informática) (1990), XII Censo General de Población y Vivienda 1990, en <http://www.inegi.gob.mx/>, marzo de 2006.

INEGI (Instituto Nacional de Estadística, Geografía e Informática) (1991), Censo agropecuario de Baja California, México, AGROS, cd-rom. 
INEGI (Instituto Nacional de Estadística, Geografía e Informática) (2000), XII Censo General de Población y Vivienda 2000, en <http://www.inegi.gob.mx/>, marzo de 2006.

INEGI (Instituto Nacional de Estadística, Geografía e Informática) (2005), Industria maquiladora de exportación, en <http:/ /dgcnesyp.inegi.gob.mx/cgi-win/bdieintsi.exe/ NIVJ150002000300050005\#ARBOL?c=1414>, marzo de 2006.

Keeley, E. Jon y Sterling C. Keeley (1984), "Postfire recovery of California coastal sage scrub", American Midland Naturalist, 97, University of Notre Dame, Indiana, pp. 120-132.

Lepart, Jacques y Max Debussche (1992), "Human impact on landscape patterning: Mediterranean examples", en A. J. Hansen y F. di Castri (eds.), Landscape Boundaries. Consequences for Biotic Diversity and Ecological Flows, Springer Verlag (Nueva York), pp. 77-106.

Lorey, David E. (ed.) (1990), United States Mexico Border Statistics since 1900, UCLA-Latin American Publications (California).

Luomala, Katharine L. (1978), “'Tipai-Ipai' in California”, en R. F. Heizer (ed.), Handbook of North American Indians, vol. 8, Smithsonian Institution, Washington, D.C., pp. 592-609.

Meling-Pompa, David (1991), "La ganadería en la Sierra San Pedro Mártir”, en E. Franco-Vizcaíno y J. Sosa-Ramírez (eds.), El potencial de la cordillera peninsular de las Californias como reserva de la biosfera, memorias de congreso, CICESE CIEC09101, Ensenada, B.C., pp. 14-16.

Meyer, B. William y Billie Lee Turner II (1990), "Editorial Introduction of chapter III", en B. L. Turner II, W. C. Clark, R. W. Kates, J. F. Richards, J. T. Mattews y W. B. Meyer (eds.), The Earth as Transformed by Human Action. Global and Regional Changes in the Biosphere over the Past 300 years, Cambridge University Press, Cambridge. 
Michel, Susan (2002), "The Geography of water transfers and urbanization in Baja and southern California”, en L. Fernández y R. T. Carson (eds.), Both Sides of the Border, Kluwer Academic Press (Países Bajos), pp. 199-234.

Mills, James (1967), “San Diego... where California began”, The Journal of San Diego History, 13(4), p. 35, en <http:// sandiegohistory.org/journal/67october/began.htm >, marzo de 2006.

Minnich, Richard (1983), "Fire mosaics in southern California and Northern Baja California", Science, 219, American Association for the Advancement of Science, Washington, D.C., pp. 1287-1294.

Minnich, Richard (1988), "The biogeography of fire in the San Bernardino Mountains of California. A historical study", Geography, 28, University of California Press, California, p. 120.

Minnich, Richard y Ernesto Franco-Vizcaíno (1998), "Land of Chamise and Pines. Historical Accounts and Current Status of Northern Baja California's Vegetation”, Botany, 80, University of California Press, California.

Minnich, Richard y Ernesto Franco-Vizcaíno (2002), “Divergence in California vegetation and fire regimes induced by differences in fire management across the U.S.-Mexico Boundary”, en L. Fernández y R. T. Carson (eds.), Both sides of the Border, Kluwer Academic Publisher (Países Bajos), pp. 385-402.

MSCP (Multiple Species Conservation Program) (2003), “County of San Diego Subarea Plan, Natural Community Conservation Planning, San Diego County", San Diego, CA, vi+113 pp.

Ojeda, Lina (2000), "Landuse and the conservation of natural resources in the Tijuana River Basin”, en Lawrence Herzog, Shared Spaces: Mexico-United States Environmental Future, Center for U.s. Mexico Studies, San Diego, pp. 211-232. 
Ojeda, Lina (2002), "Habitat fragmentation in the Tijuana River Watershed (1953-1994)", en Paul Ganster, Felipe Cuamea, José Luis Castro y A. Villegas (eds.), Tecate, Baja California: Realities and challenges in a Mexican Border Community, San Diego State University Press-Institute for Regional Studies of the Californias, San Diego, pp. 163-176.

Ojeda, Lina, Gerardo Bocco, Ezequiel Ezcurra e Ileana Espejel (2007), "Land-cover/use transitions in the binational Tijuana River watershed during a period of rapid industrialization", Applied Vegetation Science, doi: 10.3170/20077-18331, publicado en línea el 13 de diciembre de 2007, IAVS, Opulus Press, Uppsala, 10 pp.

O’Leary F., John (1990), "Postfire diversity patterns in two subassociations of California coastal sage scrub", Journal of Vegetation Science, 1, Opulus Press, Uppsala, pp. 72-180.

Olmstead, Alan L. y Paul W. Rhode (2004), "The evolution of California Agriculture 1850-2000”, en J. Seibert (ed.), California Agriculture: Dimensions and Issues. Cooperative Extension. Agricultural \& Resources Economics, California, University of California at Berkeley, pp. 1-28 [http:/ /are.berkeley.edu/extension/giannini/Chapter1.pdf].

Páez Frías, Elías (2005), Procesos en la estructuración del espacio metropolitano: hacia la definición de un modelo de planeación y gestión para la zona metropolitana Tijuana-Rosarito-Tecate, B.C., tesis de maestría en arquitectura, Mexicali, B.C., Universidad Autónoma de Baja California.

POE (Periódico Oficial del Estado de Baja California) (1995), Versión abreviada del Programa de Ordenamiento Ecológico del Estado de Baja California, 8 de septiembre de 1995, sección 3, Mexicali, B.c.

POE (Periódico Oficial del Estado de Baja California) (2004), Plan Estatal de Desarrollo Urbano de Baja California, t. cXI, 43, 8 de octubre de 2004, Mexicali, B.C. 
POE (Periódico Oficial del Estado de Baja California) (2005), Programa de Ordenamiento Ecológico del Estado de Baja California, t. cXII, 46, 21 de octubre de 2005, Mexicali, B.C.

Piñera, Ramírez D. (1991), Ocupación y uso del suelo en Baja California, de los grupos aborígenes a la urbanización dependiente, Universidad Nacional Autónoma de MéxicoUniversidad Autónoma de Baja California, México.

Piñera, David y Jesús Ortiz (1985), Historia de Tijuana. Semblanza general, Universidad Nacional Autónoma de México-Universidad Autónoma de Baja California, México.

Ranfla González, Arturo y Guillermo B. Álvarez de la Torre (1986), "Expansión física, formas urbanas y migración en el desarrollo urbano de Tijuana", Ciencias Sociales, serie 3, cuaderno 2, Baja California, Universidad Autónoma de Baja California, México.

Rodríguez Estévez, José Manuel (1996), Análisis del paisaje en la frontera norte de México: el caso del Valle de las Palmas, tesis de maestría en administración integral del ambiente, Tijuana, в.C., Colef-Cicese.

Rogers, Jennings Malcolm (1945), "An Outline of Yuman Prehistory", Southwestern Journal of Anthropology, 1, University of New Mexico, Albuquerque, Nuevo México, pp. 167198.

Rogers, Jennings Malcolm (1966), Ancient Hunters of the Far West, Copley Press, San Diego, California.

Salas, Alejandra (1989), Nuestra frontera norte, Nuestro Tiempo, México.

SDSU (San Diego State University)-Colef (El Colegio de la Frontera Norte) (2005), Atlas de la cuenca del río Tijuana, San Diego University Press-Institute for Regional Studies of the Californias, San Diego.

Sandag (San Diego Association of Governments) (2000), http:// datawarehouse.sandag.org/. 
Santiago-Guerrero, Bibiana Leticia (2002), "Perfil del origen de la población de Tecate”, en Paul Ganster, F. Cuamea, J. L. Castro y A. Villegas (comps.), Tecate, Baja California: realidades y desafíos de una comunidad mexicana fronteriza, San Diego State University Press (San Diego), pp. 3-17.

Secretaría de la Economía Nacional (1942), Segundo censo ejidal de los Estados Unidos Mexicanos, 6 de marzo de 1940, Territorio Norte, Baja California, México.

Serra, Junípero (1955), Writings of Junipero Serra, ed. de Antoine Tibesar, Academy of American Franciscan History, vol. 1, Washington, D.C.

Shipek, Florence (1969), "Kumeyaay Socio-Political Structure”, Journal of California and Great Basin Anthropology, 4(2), Malki Museum, Banning, California, pp. 296-303.

Shipek, Florence (1993), "Kumeyaay plant husbandry: fire, water, and erosion control systems", en C. T. Blackburn y K. Anderson (comps.), Before the Wilderness. Environmental Management by Native Californians, Ballena Press (California), pp. 379-388.

Shugart, H. Herman (1998), Terrestrial Ecosystems in Changing Environments, Cambridge University Press, Cambridge.

Sokolow, Alvin (2004), "California's Edge Problem: Urban Impacts on Agriculture", en J. Seibert (ed.), California Agriculture: Dimensions and Issues. Cooperative Extension. Agricultural \& Resources Economics, University of California at Berkeley (California), pp. 289-304.

Trava Manzanilla, José Luis, Jesús Román Calleros y Francisco A. Bernal (comps.) (1991), Manejo ambientalmente adecuado del agua. La frontera México-Estados Unidos, El Colegio de la Frontera Norte, Baja California.

Treganza, Adán (1947), Notes on the San Dieguito lithic industry of southern California and northern Baja California, University of California Publications in American Archaeology and Ethnology (California), 44. 
Turner II, William C. Clark, Robert W. Kates, John F. Richards, Jessica T. Mattews y William B. Meyer (eds.) (1990), The Earth as Transformed by Human Action. Global and Regional Changes in the Biosphere over the Past 300 years, Cambridge, Cambridge University Press.

Webster, L. Grady y Conrad J. Bahre (2001), Changing Plant Life of La Frontera. Observations on Vegetation in the US/ Mexico Borderlands, Albuquerque, University of New Mexico Press.

Zenteno Quintero, René y Rodolfo Cruz Piñeiro (1992), "Boom in the Midst of the Bust: Well-Being in Tijuana", en H. A. Selby y H. Browning, The Sociodemographic Effects of the Crisis in Mexico, Austin, University of Texas at Austin, http://lanic.utexas.edu/project/etext/mexico/selby/ chap7.html.

Recibido: 7 de agosto de 2006. Reenviado: 21 de marzo de 2007. Aceptado: 23 de mayo de 2007.

Lina Ojeda-Revah. Es doctora por la Universidad Autónoma de Baja California (UABC); estudió la licenciatura en biología en la Universidad Autónoma Metropolitana (UAM) y la maestría en ciencias en la Universidad Nacional Autónoma de México (UNAM); tiene un máster en gestión medioambiental del Instituto de Investigaciones Ecológicas de Málaga, España, y es egresada del programa Leadership for Environment and Development (LEAD) de El Colegio de México. Actualmente es investigadora del Colegio de la Frontera Sur y se desempeña como encargada del Departamento de Vinculación. Ha publicado 30 trabajos en revistas nacionales e internacionales en coautoría con colegas de diversas profesiones. Sus líneas de investigación son: parques urbanos y cambio de uso de suelo de la cuenca del río Tijuana, tema sobre el cual ha publicado: "Habitat fragmentation in the Tijuana River Watershed (1953-1994)", en P. Ganster, F. Cuamea, J. L. Castro y A.Villegas, Tecate, Baja California: Realities and challenges in a Mexican Border Community, San Diego, San Diego State University Press-Institute for Regional Studies of the Californias, pp. 163-176 (2002); "Land cover/use transitions in 
the binational Tijuana River Watershed during a period of rapid industrialization. Applied Vegetation Science”, doi: 10.3170/ 2007-7-18331, publicado en línea el 13 de diciembre de 2007, 10 pp. Opulus Press, Uppsala.

Martha Ileana Espejel-Carbajal. Es doctora por la Universidad de Uppsala, Suecia; estudió la licenciatura en biología en la Universidad Nacional Autónoma de México (UNAM) y es egresada del programa Leadership for Environment and Development (LEAD) de El Colegio de México. Actualmente es profesora de la Facultad de Ciencias de la Universidad Autónoma de Baja California e investigadora nivel I del Sistema Nacional de Investigadores (sNI). Sus líneas actuales de investigación son: manejo integral costero, docencia en ecología del paisaje y manejo integral de ecosistemas de zonas áridas y costeras. Ha publicado 80 trabajos en revistas nacionales e internacionales en coautoría con alumnos y colegas de diversas profesiones en distintos temas sobre manejo de ecosistemas costeros y de zonas áridas. En lo que se refiere al tema de este artículo, se mencionan las publicaciones: "Propuesta para un nuevo municipio con base en las cuencas hidrográficas", Gestión y Política Pública, xvI, CIDE, México, pp.129-168 (2005); "Dinámica en el uso del suelo en tres ejidos cercanos a la ciudad de Chetumal, Quintana Roo", Revista de Geografía, 58, Universidad Nacional Autónoma de México, México, pp. 122-139 (2006). 